NASA Technical Memorandum 106272

$$
\begin{aligned}
& 1 N-20 \\
& 176657
\end{aligned}
$$

AIAA-93-1936

$$
\text { p. } 18
$$

\title{
NASA's Progress in Nuclear Electric Propulsion Technology
}

James R. Stone, Michael P. Doherty and Keith M. Peecook Lewis Research Center Cleveland, Ohio

Prepared for the 29th AIAA Joint Propulsion Conference and Exhibit cosponsored by the AIAA, SAE, ASME and ASEE June 28-30, 1993, Monterey, California 


\title{
NASA'S PROGRESS IN NUCLEAR ELECTRIC PROPULSION TECHNOLOGY
}

\author{
James R. Stone,* Michael P. Doherty** and Keith M. Peecook*** \\ Nuclear Propulsion Office \\ NASA Lewis Research Center \\ Cleveland, $\mathrm{OH} 44135$
}

\begin{abstract}
The National Aeronautics and Space Administration (NASA) has established a requirement for Nuclear Electric Propusion (NEP) technology for robotic planetary science mission applications with potential future evolution to systems for piloted Mars vehicles. To advance the readiness of NEP for these challenging missions, a near-term flight demonstration on a meaningful robotic science mission is very desirable. This paper briefly reviews the requirements for both near-term and outer planet science missions and describes the nearterm baseline system established under a recent study jointly conducted by the Lewis Research Center (LeRC) and the Jet Propulsion Laboratory (JPL). Technology issues are identified where work is needed to establish the technology for the baseline system, and technology opportunities which could provide improvement beyond baseline capabilities are discussed. Finally, the plan to develop this promising technology is presented and discussed.
\end{abstract}

\section{Introduction}

The National Aeronautics and Space Administration (NASA) has established a requirement for Nuclear Electric Propusion (NEP) technology for applica- tion to planetary space science missions with potential future evolution to systems for piloted Mars vehicles. To advance the readiness of NEP for these challenging missions, a near-term flight demonstration as a part of a meaningful science mission is very desirable.

Nuclear propulsion has been identified as a key enabling technology for human and robotic exploration of the solar system by the Advisory Committee On the Future of the U.S. Space Program. ${ }^{1}$ The Synthesis Group on America's Space Exploration Initiative ${ }^{2}$ established Nuclear Thermal Propulsion (NTP) as thepreferred approach for human exploration of Mars and also identified NEP as a high payoff technology which should be pursued. However, the major emphasis of the current NEP Program is on meeting the requirements for missions of the type studied by Yen and $\mathrm{Sauer}^{3}$ for $50-100 \mathrm{~kW}$ systems. NASA initiated a program to establish the readiness of nuclear propulsion for application to piloted and robotic science missions throughout the solar system. This program was initiated in Fiscal Year (FY) 1991 with modest effort on NTP and was extended to include NEP in FY 1992. NEP activities have been underway at modest funding level in NASA's Base Research and Technology (R\&T) Program (for example, see ref. 4 ), in the

\footnotetext{
- Associate Fellow, AIAA

* Member, alaA

** Non-member

Copyright $(\mathcal{O} 1993$ by the American Institute of Aeronautics and Astronautics, Inc. No copyright is asserted in the United States under Title 17, U.S. Code. The U.S. Government has a royaltyfree license to exercise all rights under the copyright claimed herein for government purposes. All other rights are reserved to the copyright owner.
} 
Civil Space Technology Initiative (CSTI) High Capacity Power Program5, and in the Department of Energy (DOE)/ Department of Defense (DoD)/NASA SP. 100 space nuclear power program. Planning for the NEP program was initiated with a workshop held at the Jet Propulsion Laboratory (JPL) in July $1990 ; 11$ power subsystem concepts were reviewed along with 10 propulsion subsystem concepts.6,7

The NEP Technology Program in FY 1992 focused on the thruster/power processor subsystem and relied on the interagency SP-100 program to provide the reactor and power conversion subsystem technologies. The thruster technology was primarily focused on inert-gas ion propulsion for application to Space Science missions. Supporting efforts in thermal management and hightemperature electronics were also undertaken. Funding for NEP technology development was not continued in FY 1993, and NEP activity has been limited to studies focused on 20 $50 \mathrm{~kW}_{\mathrm{e}}$ systems for early science missions which could evolve to 50-100 $\mathrm{kW}$ e for outer planet missions. Very recently interest has re-emerged in multimegawatt systems for cargo and piloted vehicles.

This paper briefly reviews the requirements for the low power missions and describes the baseline system developed in recent studies conducted by the Lewis Research Center (LeRC) and JPL. Technology issues are identified where work is needed to establish the technology for the baseline system, and technology opportunities which could provide improvement beyond baseline capabilities are discussed. The baseline technology for the precursor mission should be clearly evolvable to the outer planet missions. Finally, the plan to develop this promising technology is presented and discussed. Earlier progress in this program is reported in references 8 and 9 .

Although the Russian-developed Topaz II thermionic power system could conceivably be considered to power a near-term mission, its mass is too great and its lifetime too short to be useful in the missions of interest and much more significant improvements would be required for that approach than for an SP-100 system to meet the outer planet mission requirements.

\section{Recent Studies}

Mission and system studies assuming the use of SP-100 reactor and power conversion technologies and ion electric propulsion have been performed which show that NEP enables a number of the proposed missions (Friedlander ${ }^{10}$ ) and allows for robotic orbiter missions to the major satellites of Jupiter, Uranus, Neptune, and Pluto (Yen and Sauer ${ }^{3}$ ), and yields more frequent launch opportunities. These analyses have shown that successful performance of the desired robotic outer planetary missions will require a space nuclear electric power source rated nominally at 7 to 10 years full power life, $50-100 \mathrm{~kW}_{e}$ power and $25 \mathrm{~W} / \mathrm{kg}$ specific power with ion engines having specific impulse, $I_{s p}$, of 5,000 to $10,000 \mathrm{~s}$, at least $8 \mathrm{~kW}_{\mathrm{e}}$ per thruster power rating, and 10,000 hours individual thruster life.

As an initial step in developing NEP for robotic outer planetary missions, a low power, early flight initiative was proposed in early FY 1993 by the Office of Space Science and Applications' Solar System Exploration Division, and a mission/system study was initiated at that organization's request. Missions initially considered under this study were those requiring just $15-50 \mathrm{~kW}_{\mathrm{e}}$ and only a 3 year reactor full power life, relying on technologies projected to be in hand by the year 1994. Missions to be considered were a Mars orbiter 
including Phobos and Deimos rendezvous, a 3-body main-belt asteroid multiple rendezvous, and a Vesta sample return.

Based on program planning guidance from an interagency (DOE/NASA) planning committee ${ }^{1} I$, the low power study focused initially upon technologies that could provide an NEP system for launch by 1998. As the study progressed the prospects for a NEP mission beginning in 1998 dimmed, and the planning guidlines were significantly changed. The reference propulsion technology, against which the benefits of NEP were to be evaluated changed from chemical to solar electric propulsion (SEP). Consequently, the playing field of technologies was widened to include NEP technologies that could be developed during the 1990s, and the mission set was expanded to include missions very clearly enabled by NEP (and not by SEP).

As a result the final mission set, presented in March 1993 by Yen, et el.12 came to include a variety of missions, as follows:

- Mars Orbiter with Phobos/Deimos Rendezvous

- Comet Kopf Rendezvous/Sample Return

- Multiple Mainbelt Asteroid Rendezvous (MMBAR)

- Vesta Sample Return

- Trojan Asteroid Rendezvous

- Jupiter Mini Grand Tour (tour of 2 outer moons)

These missions require space nuclear electric power sources ranging from 3 to 7 years in reactor full power life, 15 to 60 $\mathrm{kW}_{\mathrm{e}}$ in power, 5 to $20 \mathrm{~W} / \mathrm{kg}$ specific power, and ion engines having Isp of 3,500 to $10,000 \mathrm{~s}$ with at least $3 \mathrm{kWe}$ per thruster and 10,000 hour individual thruster life.

\section{Baseline System}

The baseline system (Fig. 1) established under the recent low power NEP mission/ system study is comprised of a space nuclear power source consisting of a lithium cooled reactor coupled with closed-cycle Brayton power conversion driving an electric propulsion subsystem consisting of $30 \mathrm{~cm}$ diameter xenon ion engines. The power subsystem is designed for $40 \mathrm{~kW}_{\mathrm{e}}$ with 3 year full power life and would provide 9 $W / \mathrm{kg}$; while the propulsion subsystem is designed for $I_{s p}$ of $5,000 \mathrm{~s}$ and 10,000 hour individual thruster life, requiring about $7 \mathrm{~kW}_{\mathrm{e}}$ per thruster.

The baseline power system is SP-100.13 The SP-100 Space Reactor Power System (SRPS) has been under development by the General Electric Company (GE), under contract to the U.S. Department of Energy, to provide power in the range of $10 \mathrm{~s}$ to $100 \mathrm{~s}$ of $\mathrm{kW}_{\mathrm{e}}$. Hardware development and testing has progressed to the point of resolving key technical feasibility issues. The technology and design is now at a state of readiness to support definition of early flight demonstration missions. The benefits of utilizing a low power $(20 \mathrm{~kW}$ e class $)$ early demonstration mission as a precursor to $100 \mathrm{~kW}$ e class operational missions has received interest among Government agencies 11 and industry ${ }^{13}$ to support these missions.

The power and propulsion subsystems are further defined as follows. The nuclear reactor is SP-100 technology uranium nitride pin-type fuel with niobium-1 percent-zirconium cladding with a core thermal power rating of about $175 \mathrm{~kW}$. The boom length to the payload dose plane is $22.5 \mathrm{~m}$. The 17 degree shield is tungsten/lithium hydride, sized to limit the neutron dose 


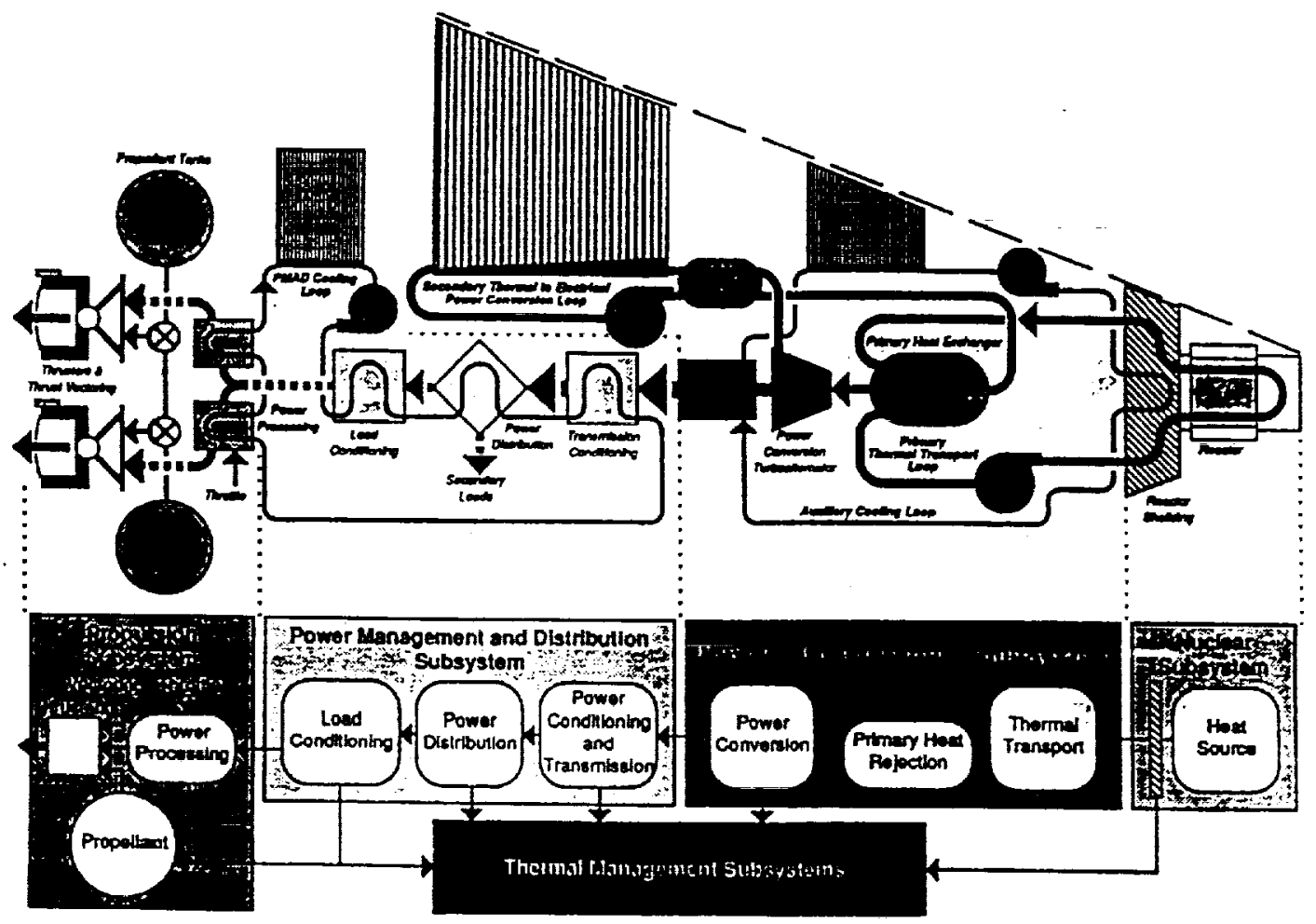

Figure 1. - NEP System Schematic. 14

and gamma dose to $10^{12}$ nvt and $10^{5} \mathrm{rad}$, respectively, at the dose plane. There are a total of 3 Brayton engines (2 required, 1 spare), each rated at $20 \mathrm{kWe}$, having $1144 \mathrm{~K}$ turbine inlet temperature with superalloy construction, thermodynamically optimized along with the heat rejection subsystem for minimum mass. The required radiator area is $190 \mathrm{~m}^{2}$, assuming a Space Station Freedom type aluminum radiator loop with pumped toluene coolant, rated at $450 \mathrm{~K}$ maximum temperature. Power management and distribution (PMAD) technology assumed is $208 \mathrm{~V}, 1200 \mathrm{~Hz} \mathrm{AC}$ power with electronics temperatures up to $373 \mathrm{~K}$.

The power subsystem, comprised of reactor, shield, power conversion, heat rejection, PMAD, and supporting structure has a mass of $4450 \mathrm{~kg}$. Table I presents the subsystem masses. To process the system rated power at $5,000 \mathrm{~s}$ Isp, the propulsion susbsystem requires 6 xenon ion engines for each 10,000 hours of full power life (18 engines in all) and 12 power processing units (100 $\%$ redundancy), resulting in a propulsion subsystem mass of $870 \mathrm{~kg}$. Overall, the entire NEP system has a specific mass (dry) of $133 \mathrm{~kg} / \mathrm{kWe}$. Figure 2 depicts the deployed spacecraft configuration.

This specific system was chosen because it was the nearest term system appearing to meet the transportation requirements of a 3-body MMBAR mission (20Massalia, 44-Nysa, 5-Astraea) having a June 1998 launch date, which is in keeping with programmatic planning guidance. 11 In general the selection of a reference mission will enable a more 
Table I - Baseline NEP System Mass Statement. 12

- $30 \mathrm{~cm}$ Xe lon, 5000 seconds

- 3 sets of 6 thrusters - 30,000 hours life

-2 sets of PPU's - 1 fully redundant

Thinusters

Thrusters

Gimbals and Structure PPU

Beam Power Suppły

Discharge Power Supply

Accel, Neutralizer Supplies

Thermal Control

interface Module

\section{No. Units}

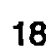

18

12

12

12

2

1

Mass (kg)

$\frac{221}{126}$

126

648

258

74

96

173

47

- 1994 BRU Technology

\section{No, Units}

Reactor

Aeactor+Salety

$18 \mathrm{C}$

Shield

Power conversion

BRU's and ducting

Hot Side HX

Recuperator+Rad. HX

Heat Rejection

PMAD

Batteries

Transmission Lines

Parasitic Load Radiator

Alternator Speed Reg.

AC Switchgear

Structure (10\%)

Total

refined science/spacecraft definition and provide focus for technology development and cost estimation.

\section{Technology Status and Issues}

Although the baseline systems utilize technologies which are thought to be achievable in the near term (for 40 $\mathrm{kW}_{\mathrm{e}}$ ) there are some issues which must be addressed before finalizing the system design, as discussed in this section. There are still more issues which must be addressed to allow the evolution to longer-life, higher

$\begin{array}{lr}1 & \frac{858}{608} \\ 1 & 250 \\ 1 & \frac{485}{1020} \\ 3 & 333 \\ 3 & 75 \\ 3 & 612 \\ 1 & \frac{1341}{347} \\ 1 & 139 \\ 3 & 24 \\ 3 & 3 \\ 3 & 90 \\ 3 & 91 \\ & \mathbf{4 0 5} \\ & \mathbf{5 3 2 0}\end{array}$

power $\left(50-100 \mathrm{~kW}_{\mathrm{e}}\right)$ systems for missions such as those to the outer planets. Of course there are many more issues to be addressed if interest reemerges in $\mathrm{MW}_{\mathrm{e}}$ class applications; Rankine cycle power conversion becomes of interest as does magnetoplasmadynamic (MPD) propulsion.

\section{Power Subsystem}

The impact of delay or termination of the SP-100 program is clearly a critical issue. In the technology area of 3 year full power reactor life, the only 


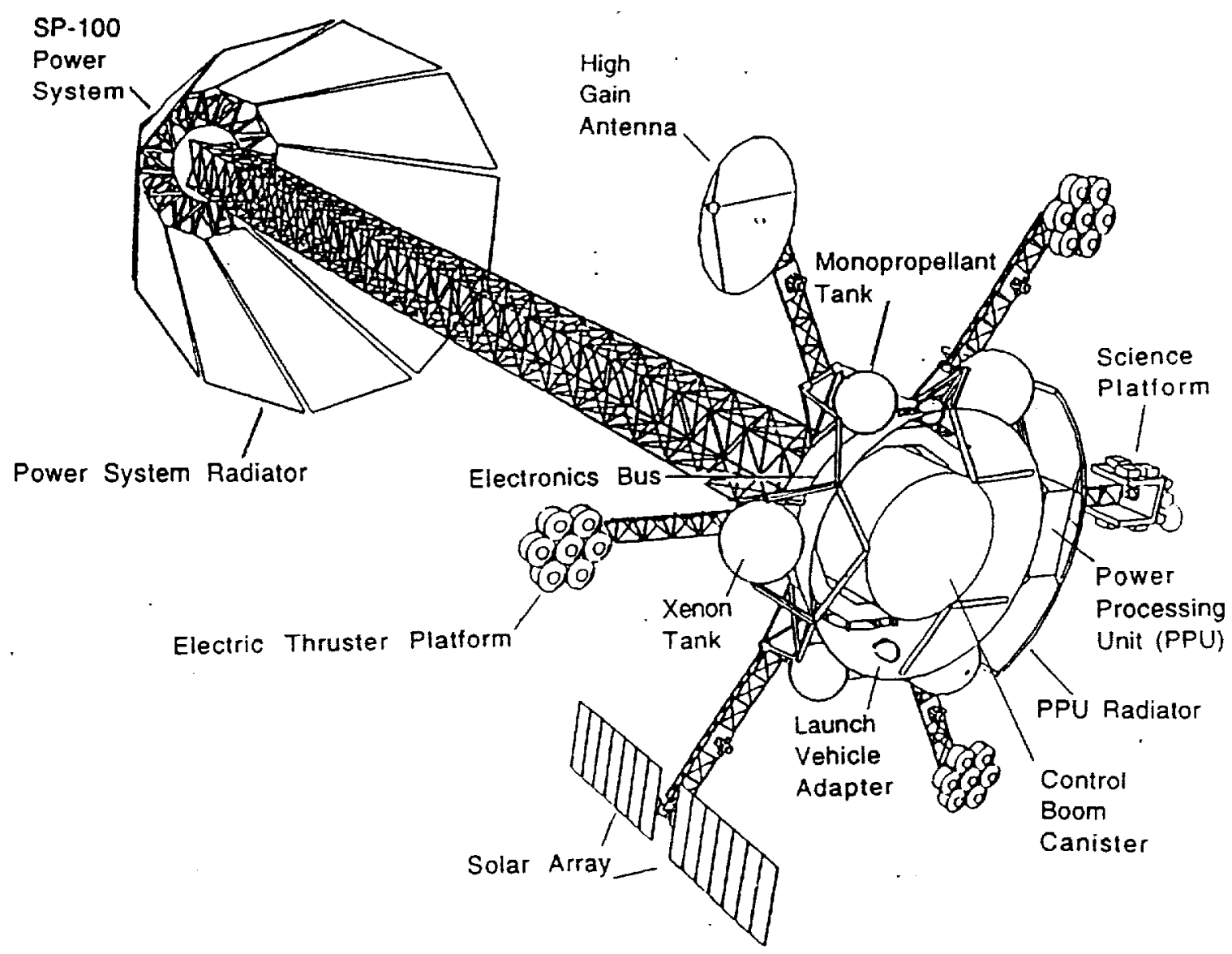

Figure 2. - NEP Vehicle in Deployed Configuration.

remaining work is to demonstrate the thermoelectric electromagnetic (TEM) pump and in-core control drive assembly in a relevant environment. For 7 to 10 year life, the life of the uranium nitride (UN) pin-type nuclear fuel still has to be demonstrated.

Some technical issues remain for power conversion also. The closed cycle Brayton power conversion system chosen for the baseline system is built around a turbo-alternator-compressor or Brayton Rotating Unit (BRU) having the same size/dimensions as that which was extensively tested by NASA Lewis Research Center in the 1970s. To uphold the credibility of a BRU-based system concept being a near-term option, a technology issues resolution plan with costs was prepared, in conjunction with the mission/system studies, to address the issue of efficient heat transfer from a $1350 \mathrm{~K}$ refractory metal alloy loop containing liquid lithium to an $1144 \mathrm{~K}$ superalloy loop containing a HeliumXenon gas mixture without material incompatibilities affecting the structural integrity of the system.15 A higher performance Brayton system, made possible by the employment of refractory metal alloys, would require a more extensive technology focus to demonstrate technical readiness. The need to continue with development of thermoelectrics as a backup to Brayton (single or muti-couple) must be considered. Thermionics may be a 
potential contender in the longer term, since theoretical efficiencies may be over 0.50 and laboratory tests have demonstrated 0.30 efficiency. The current Air Force program is aimed at 40 $\mathrm{kW}_{\mathrm{e}}$ capability.

In the thermal management area, bimetalic joints and the radiator remain as major technology development challenges. The groundrules for the recent study limited radiator options to the technology level of the Space Station Freedom radiator, which limits the possibilities for higher temperature pumped loops employing heat pipes, which would in turn effect the performance of both Brayton cycle and thermoelectric options. 16 The technol- ogy status of advanced radiators will have to be reassessed if and when a program is initiated.

In the power electronics technology area, there are no fundamental issues impacting the performance of the baseline system. The component designs were based on state of the art, Space Station Freedom component performance and operating temperatures.

\section{Propulsion Subsystem}

In the electric thruster technology area, $30 \mathrm{~cm}$ Xenon ion engine development has been supported under the NASA Base $R$ \& $T$ program for more than a decade (Fig. 3). Such thrusters have primary

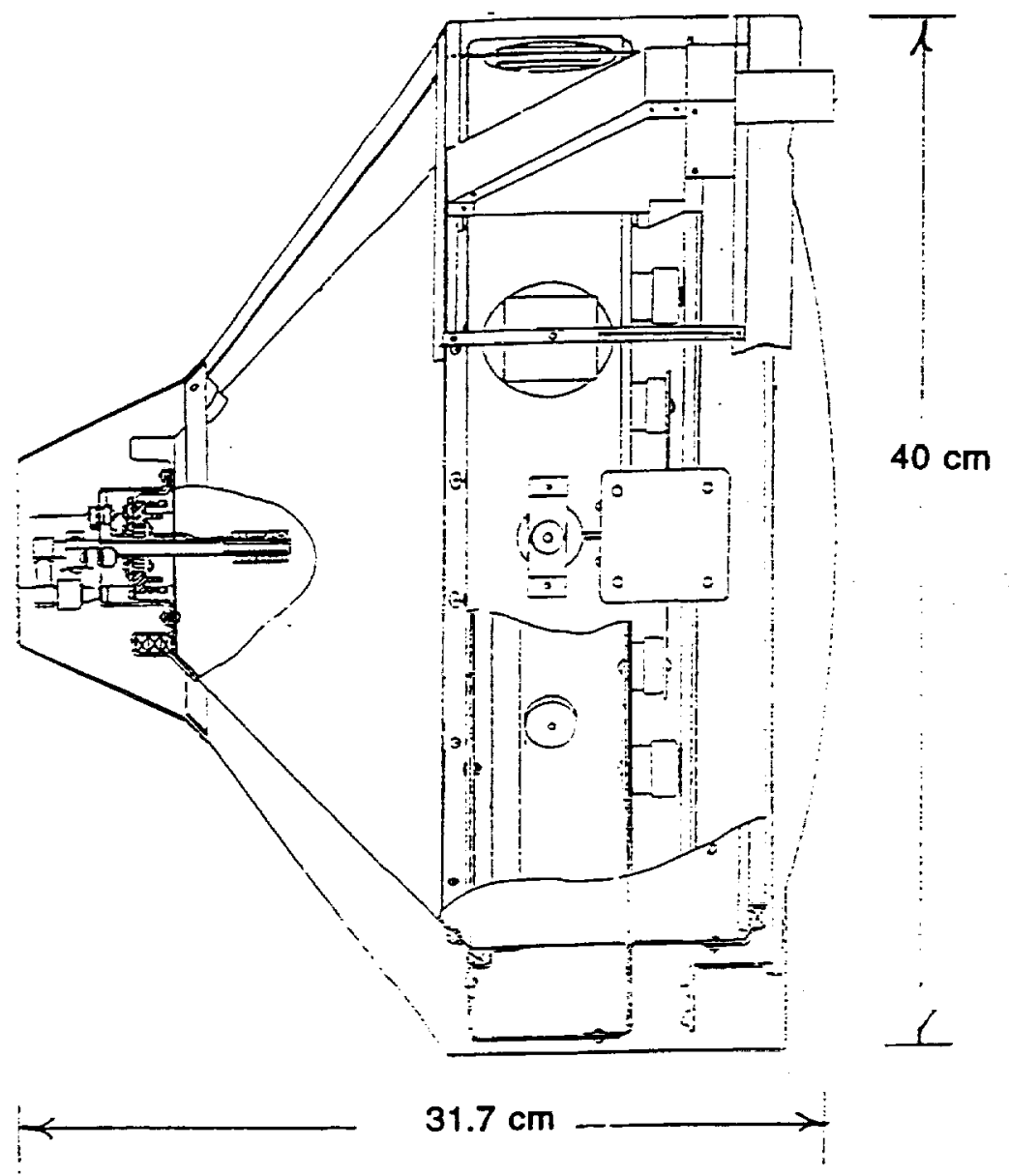

Figure 3. - 30-cm Diameter Ion Thruster Schematic. 
applications for orbit transfer, maneuvering, and planetary missions. Ion thruster $I_{s} p$ and efficiency requirements for NEP systems are expected to be about 4000 to $10,000 \mathrm{sec}$ and 65 to 75 percent, respectively, depending on power level and propellant. Technology efforts have primarily dealt with the development of long-life ion optics, cathodes, and neutralizers. Over the last five years at least five cathode life tests and three thruster wear tests have been performed by LeRC and JPL for periods of 500 to $5,000 \mathrm{hr} .9$

The need remains to demonstrate 10,000 hour thruster life, lightweight $7 \mathrm{~kW}_{\mathrm{e}}$ power processors, and xenon propellant storagefeed systems to support the low power missions. Extension of ion propulsion technology to higher power would lead to larger thruster diameters $(50 \mathrm{~cm})$ and would require particular emphasis on ion optics17-18 and power processor technologies 19 . Extension of ion propulsion technology to higher specific impulse would require a progressive shift towards Krypton and Argon as propellants, necessitating a fundamental assessment and development of lightweight storage capabilities for these propellants. Supercritical storage of argon results in unacceptablely large tankage masses, thus requiring a cryogenic storage capability that will have to last for periods of years.

In FY 1992 MPD thruster investigations were also conducted, but since no nearterm customers have been identified for this technology, the only MPD work will be that focused primarily on lithium

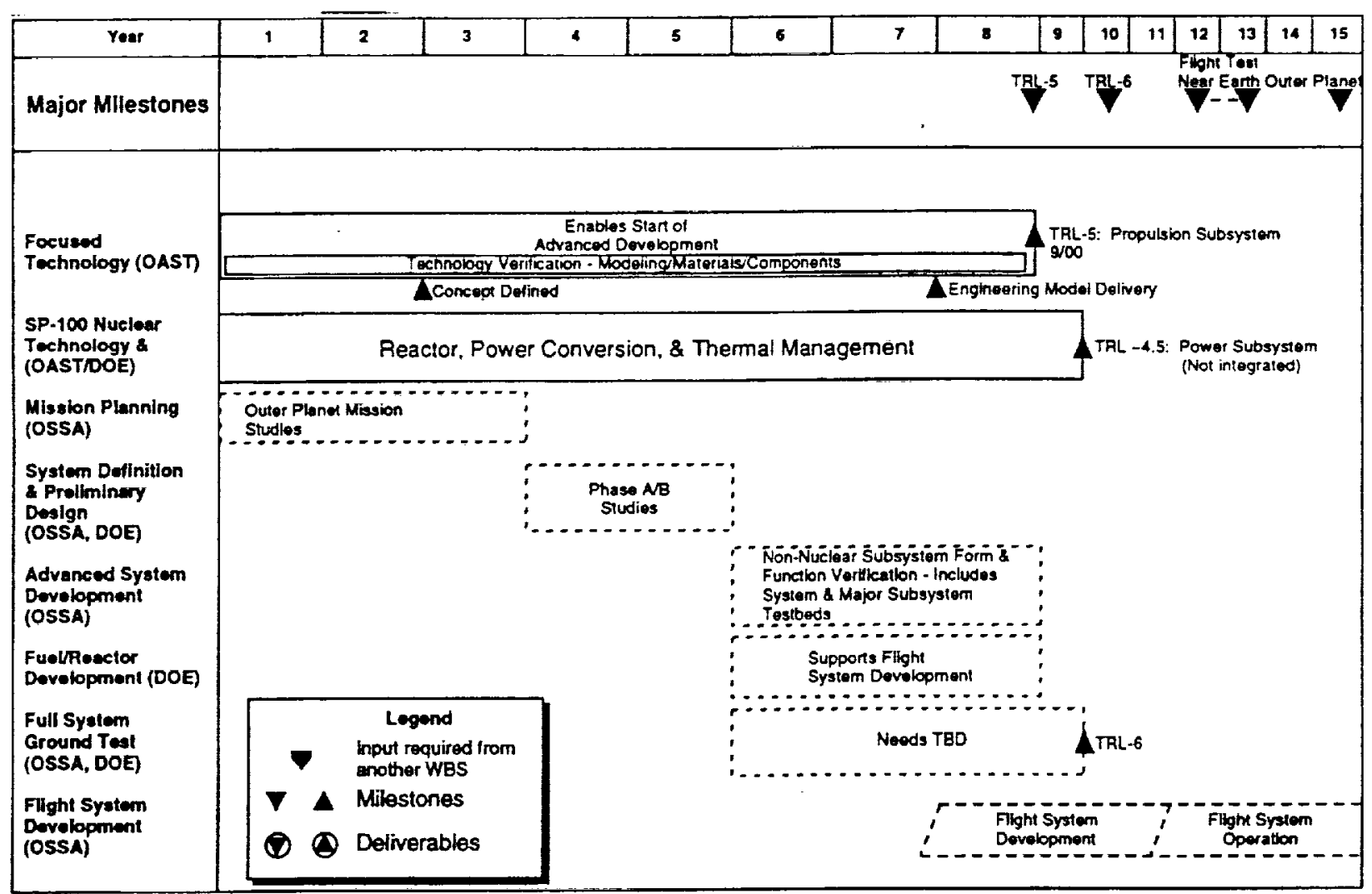

Figure 4. - NEP Overall Plan. 
propellant in the Innovative Technology program element. A more detailed, but earlier account of these activities was given in Reference 9.

Lower vacuum facility background pressures improve the accuracy of electric thruster performance measurements and also minimize facility induced erosion of the ion thruster negative grid. LeRC's $41 \mathrm{~m}^{2}$ cryopump, located in Tank 5 has been upgraded and has demonstrated closed loop operation at $20 \mathrm{~K}$ and has successfully pumped xenon, krypton, and argon. Pumping speeds were increased over the oil diffusion pumped system by a factor of 1.5 to 3. Xenon, krypton, and argon pumping speeds are now 130,00, 180,000, and 300,000 liters/s, respectively. ${ }^{9}$

\section{Technology Development Plan}

The approach to the NEP technology program is to evolve from $40-\mathbf{k W}$ to the $100 \mathrm{~kW}_{e}$ class, and ultimately to the $\mathrm{MW}_{e}$ class. In the summer of 1992 , LeRC with the participation of JPL developed a detailed plan to bring $100 \mathrm{~kW}_{\mathrm{e}}$ class NEP to the point of readiness for flight system advanced development. The overall development approach for this planning is shown in Figure 4; the planning takes into account all the activities leading to the missions, but the emphasis is on the focused technology program for the propulsion subsystem. The power subsystem, including reactor, power conversion and power thermal management would be provided by the SP-100 program or a successor program

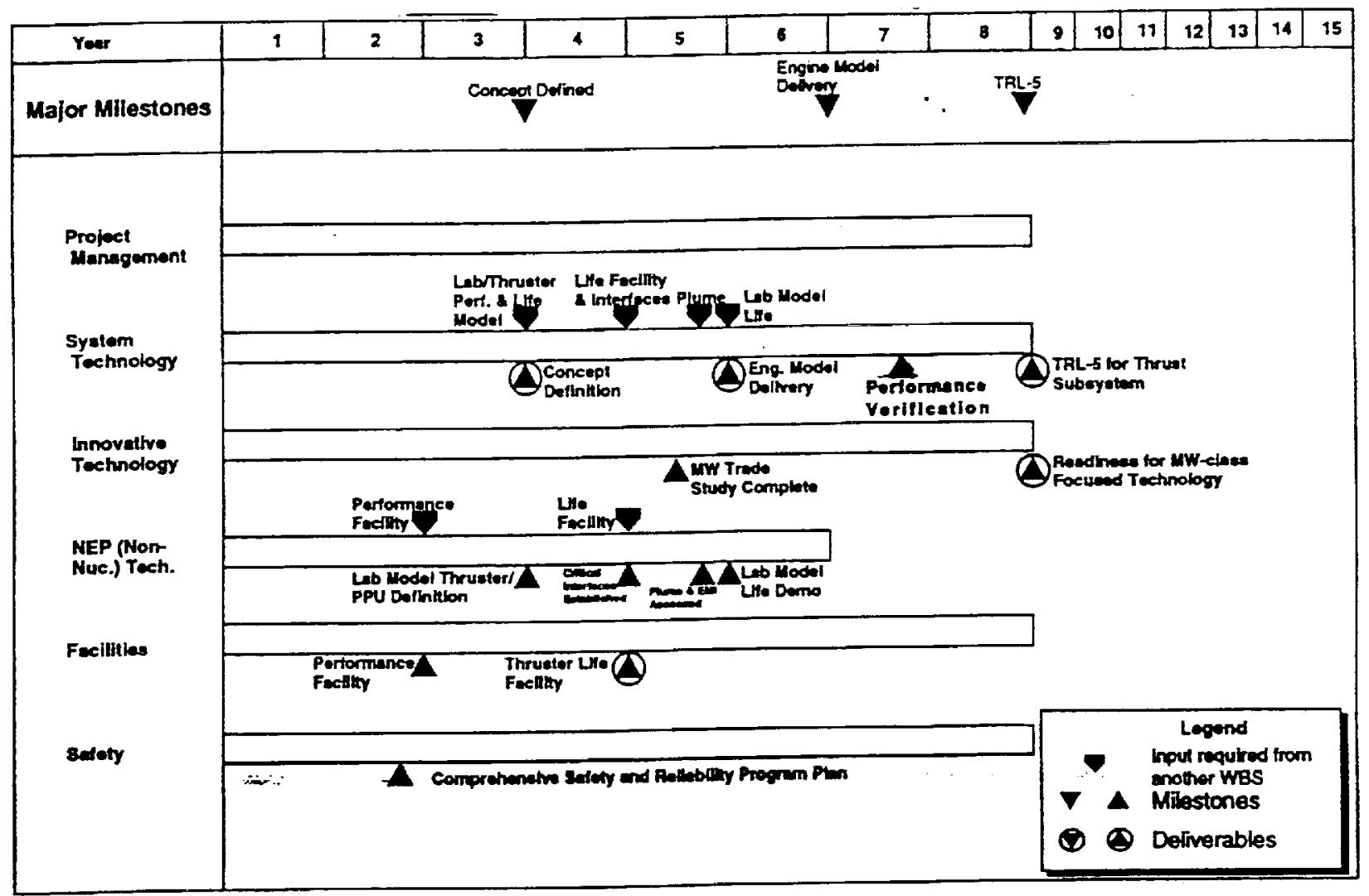

Figure 5. - NEP Focused Technology Plan - Major Elements. 
of similar scope. The original target was to demonstrate propulsion subsystem technology in the year 2000, to support possible near-Earth flight tests or precursor missions 3 to 4 years later and outer planet missions as early as 2007. This demonstration would be achieved by a full-scale thrust subsystem test in a ground-based space simulation facility, termed "Technology Readiness Level 5" or simply TRL-5. Based on planning for SP- 100 at that time, it appeared that the major components of the power subsystem would be independently tested (TRL 4.5) in 2001. However, since funding commitments for such activities are very much in doubt, the time scale shown herein is relative.

The schedule for the major subelements of the thrust subsystem focused technology development is shown in Figure 5. The approach to this effort would include the following activities:

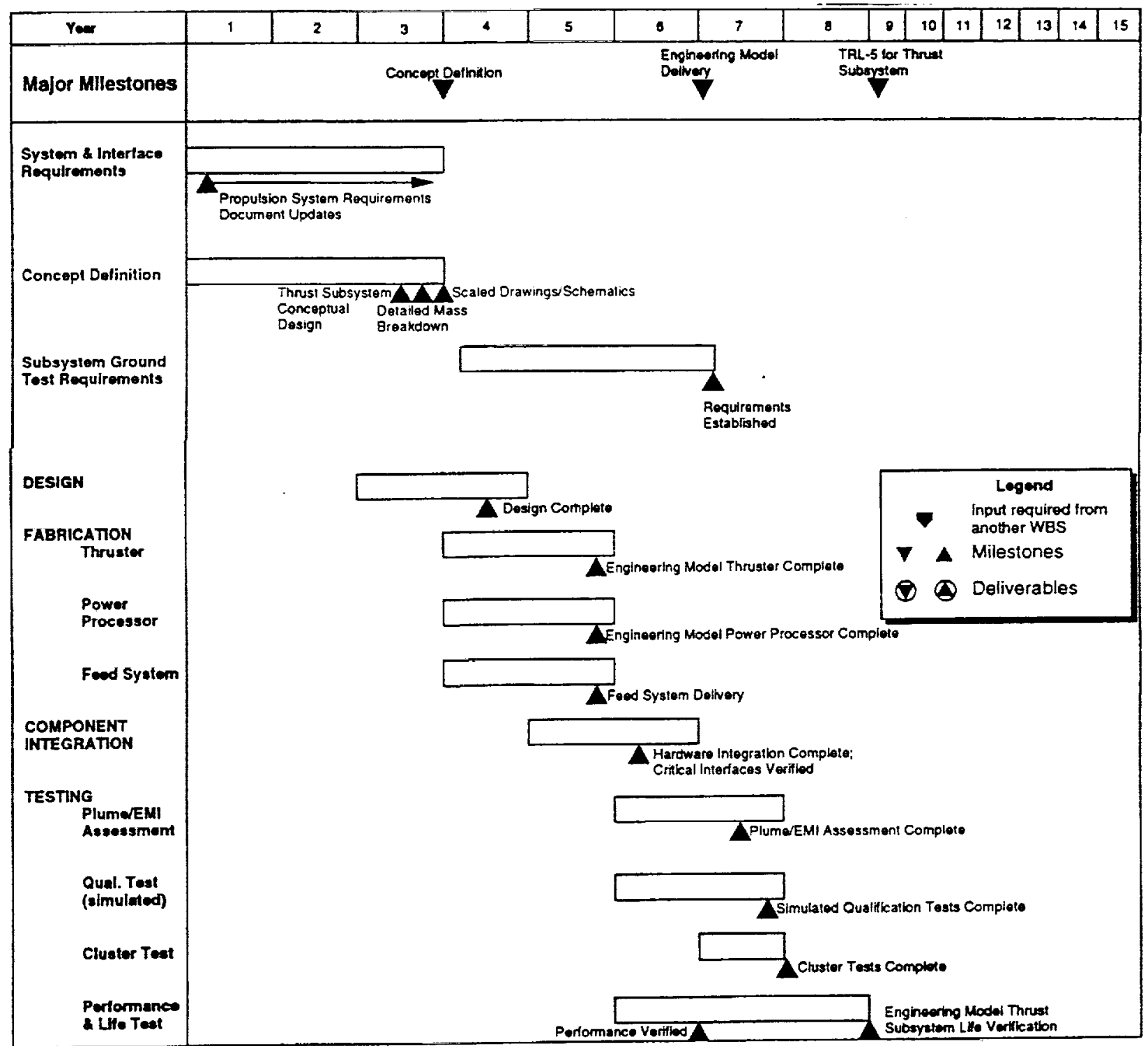

Figure 6. - NEP Systems Technology Plan 
- Laboratory experiments and supporting analyses

- Thruster

- Power processor (including thermal management)

- Interfaces

- Plumes

- Engineering model thrust subsystem ground test

- Supporting/integrating system technology studies

- Investigation of innovative technologies (including MW class)

The products and deliverables of this program are as follows:

- Trade studies and conceptual designs of NEP systems for outer planet and precursor missions (Year 3)

- Thruster size and power level selected (Year 3)

- Thruster life and performance models (Year 3)

- Laboratory model validation of design analyses and methodologies (Year 3)
- Laborarory model life demonstration (Year 5)

- Engineering model performance verification (Year 7)

- Ground-demonstrated subsystem, TRL 5 (Year 8)

The following sections describe in more detail the plans for these major elements.

\section{Project Management}

The project management activities required for this focused technology program have the objective of this element providing planing, integration and public awareness to successfully achieve the application of safe, reliable NEP for civil space missions and to integrate the technology program with with mission flight development. The approach is to establish an interagency program and develop a joint implementation plan that integrates the expertise of NASA, DOE,

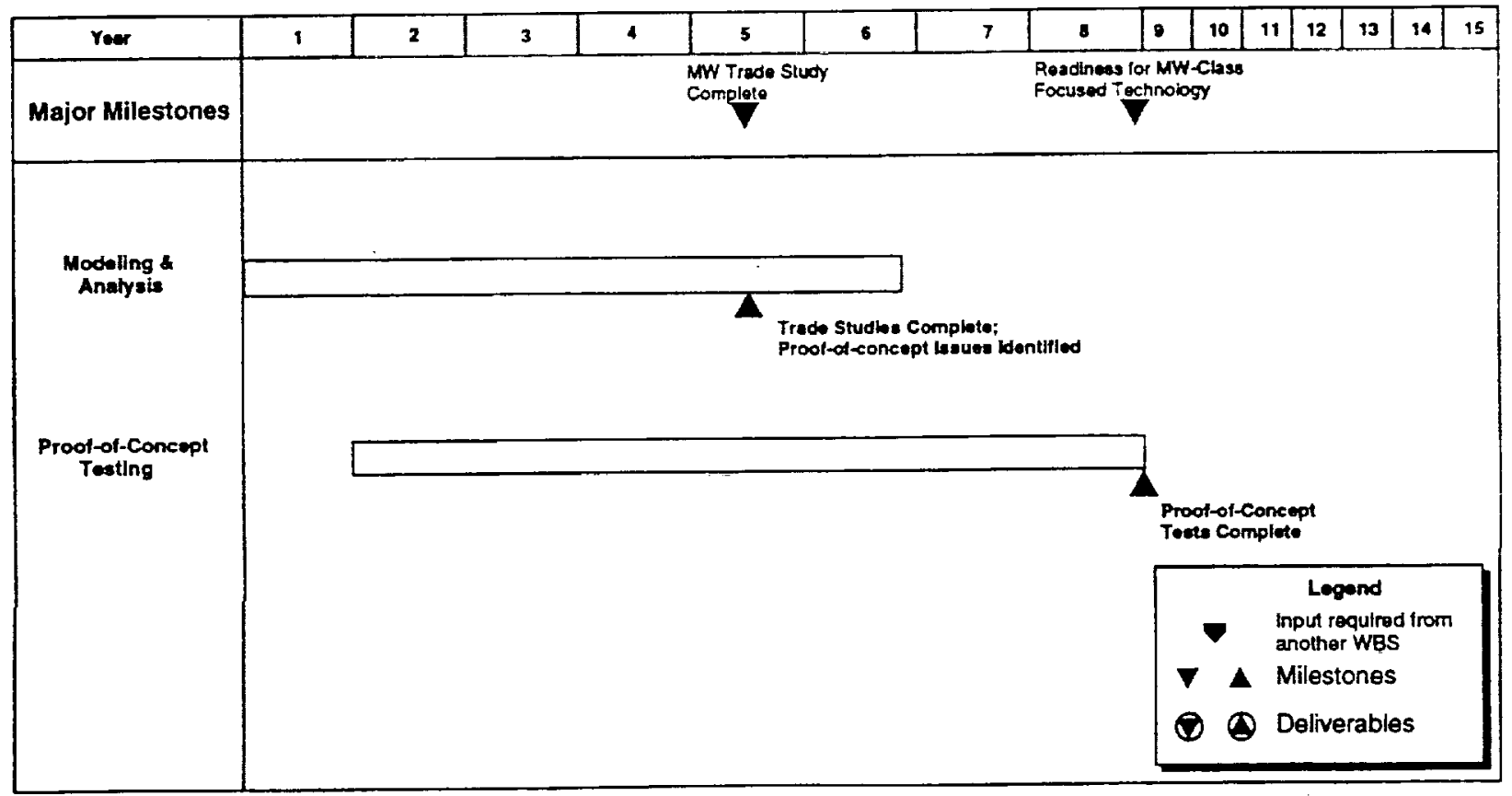

Figure 7. - NEP Innovative Technology Plan 
DoD, industry and academia to effectively achieve the program's objectives.

The products and deliverables of this element the program are as follows:

- Interagency Memorandum of Understanding signed (Year 1)

- Project Plan completed (Year 1)

- Nonadvocate review completed (Year 1)

\section{NEP Systems Technology}

There are two phases to the Systems Technology effort, the initial concept definition phase and the thrust subsystem demonstration which is the culmination of the program. The schedule for this work is shown in Figure 6.

The objective of the concept definition phase is to provide concept and system definition for the NEP system and stage to meet the requirements of the science mission or set of missions. NEP systems will be evaluated for various potential science missions and requirements, and the applicability of a common NEP stage for a set of missions will be investigated. A system/vehicle conceptual design will be developed and thrust subsystems requirements identified.

The products and deliverables of this element the program are as follows:

- Systems requirements (ongoing, updated as necessary)

- Conceptual design of NEP stage/ vehicle (Year 3)

- Scaled drawings/schematics

- Detailed mass breakdown

- Thrust subsystem conceptual

design

- Ground test requirements for thrust subsystem (Year 6)

The objectives of the thrust subsystem demonstration phase are to develop an
Engineering Model thrust subsystem and test it in LeRC's space simulation facilities. The thrust subsystem, to be designed and fabricated by an industry contractor, would include the thrusters, power processors, and the propellant feed system. Testing would include life and performance, simulated flight qualification, plume and field compatibility, and thruster clustering.

The products and deliverables of this element the program are as follows:

- Definition of critical interfaces (Year 4)

- Engineering Model thrust subsystem hardware (Year 7)

- Life and performance verified in simulated environment (Year 8)

- Documentation in the form of drawing packages, assembly procedures, assembly records, and reports (Year 8)

\section{Innovative Technology}

The objective of this effort is to provide a consistent comparison of various innovative, including the $\mathrm{MW}_{\mathrm{e}}$-class systems, and to identify high payoff technologies applicable to second or third generation NEP systems. The emphasis would be on multimegawatt systems with potential application to piloted and robotic planetary transportation systems. The schedule for this activity is shown in Figure 7. The feasibility of innovative technologies would be assessed through modeling and analyses, leading to the identificaion of requirements for proof-of-concept tests. The proof-of-concept tests would be conducted and the results analyzed. The most promising concepts would then become candidates for further development.

The products and deliverables of this element the program are as follows: 
- Analytical assessments and proof-ofconcept test identification for various concepts

- Experimental evaluations of feasibilty for selected concepts

- Project plans for further development of most promising of feasible concepts

\section{NEP Thrust Subsystem Component}

\section{Technology}

The objective of this effort is to advance non-nuclear components and related technologies to enable contractor development of an engineering model thrust subsystem. The schedule for these tasks is shown in Figure 8. Performance and life issues will be evaluated for thruster, power processors, feed system, and related subcomponents. Models will be developed for performance and life. Laboratory-class hardware will be used to verify the models, to verify critical interfaces, and to address plume and electromagnetic interference (EMI) issues.

The products and deliverables of this element the program are as follows:

- Definition of technology for Engineering Model thrust subsystem (Year 3)

- Performance and life models (Year 3)

- Critical interface definition (Year 4)

- Plume/EMI assessment (Year 5)

- Laboratory Model verification of thrust subsystem performance and life (Year 5)

\section{NEP Facilities}

The objective of this effort is to ensure that the necessary non-nuclear facilities are available for ground testing of all

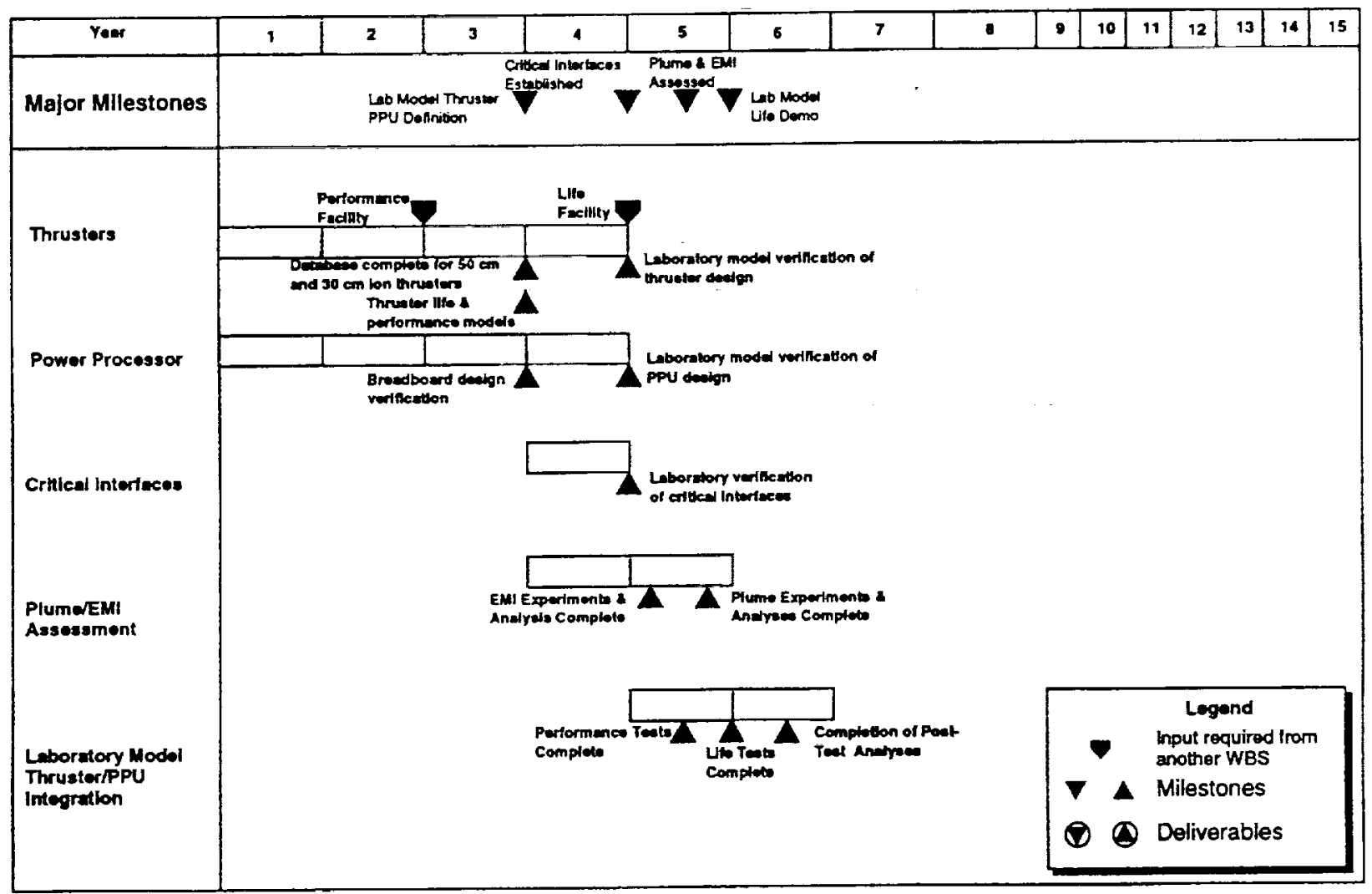

Figure 8. - NEP Thrust Subsystem Component Technology Plan 
among all program participants and throughout all aspects of the program. Safety, reliability, and quality will be "designed and built in," not "added on."

The products and deliverables of this element the program are as follows:

- Comprehensive Safety/Reliability/ Quality Program Plan (Year 2)

- Safety/Reliability/Risk assessments as an integral part of design process

- Identification of safety/reliability testing requirements as appropriate

\section{Concluding Remarks}

To advance the readiness of NEP for challenging outer planet science missions, mission/system studies were performed by the Lewis Research Center and the Jet Propulsion Laboratory and a ground-based technology demonstration plan was developed. A $40 \mathrm{~kW}$ nuclear electric propulsion vehicle was baselined which would be capable of performing several missions of interest to the space science community. The technology in this vehicle would be readily evolvable to the $50-100 \mathrm{~kW}_{\mathrm{e}}$ class systems required for even more challenging and longer duration missions to the outer planets. The technology plan presented herein would demonstrate the thrust subsystems technology, which along with power technology from the SP-100 progam or a successor, would enable these missions.

\section{Acknowledgements}

The efforts of the mission/system study team at NASA LeRC and JPL, coordinated by the second author is greatfully acknowledged and includes John Clark, Jeff George, Jim Sovey, John Smith,

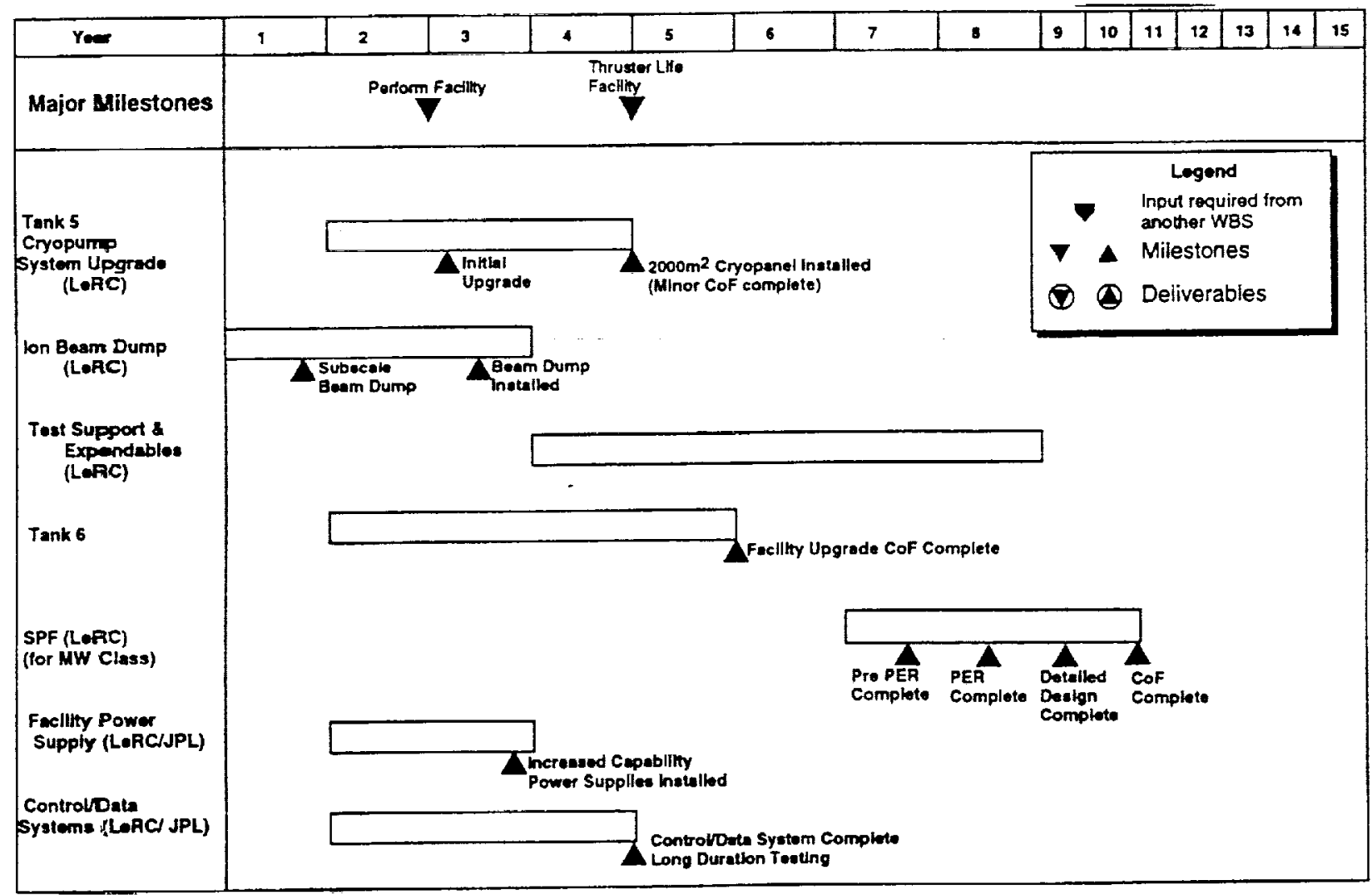

Figure 9. - NEP Facilities Plan 
Harvey Bloomfield, Bob Sefcik of LeRC, Jim Gilland and Casey Hanlon of Sverdrup Technology at LeRC,Jack Stocky, Chen-Wan Yen, Rich Ewell, Al Marriott, Jack Mondt, Kendra Short, Steve Johnson, and John Brophy of JPL. Jim Sovey and John Brophy also contributed strongly to the development of the technology plan.

\section{References}

1. Advisory Committee on the Future of the U.S. Space Program Report of the Advisory Committee on the Future of the U.S. Space Program, U.S.

Government Printing Office,

Washington, DC, 1990.

2. Synthesis Group On America's Space Exploration Initiative, "America at the Threshold," Report of the Synthesis Group On America's Space Exploration Initiative, U.S.
Government Printing Office, Washington, DC, 1991.

3. Yen, C.-W. and C.G. Sauer, "Nuclear Propulsion for Future NASA Space Science Missions," IEPC Paper 91-035, AIDAA/AIAA/DGLR/JSASS 22nd International Electric Propulsion Conference, Viareggio, Italy, October 1991.

4. Stone, J.R. and G.L. Bennett (1989) "The NASA Low Thrust Propulsion Program," AIAA Paper 89-2492, AIAA/ASME/SAE/ASEE 25th Joint Propulsion Conference, Monterey, CA, 10-14 July 1989.

5. NASA (1988) Technology for Future NASA Missions: Civil Space Technology Initiative (CSTI) and Pathfinder, NASA CP-3016, Washington, DC, 12-13 September 1988.

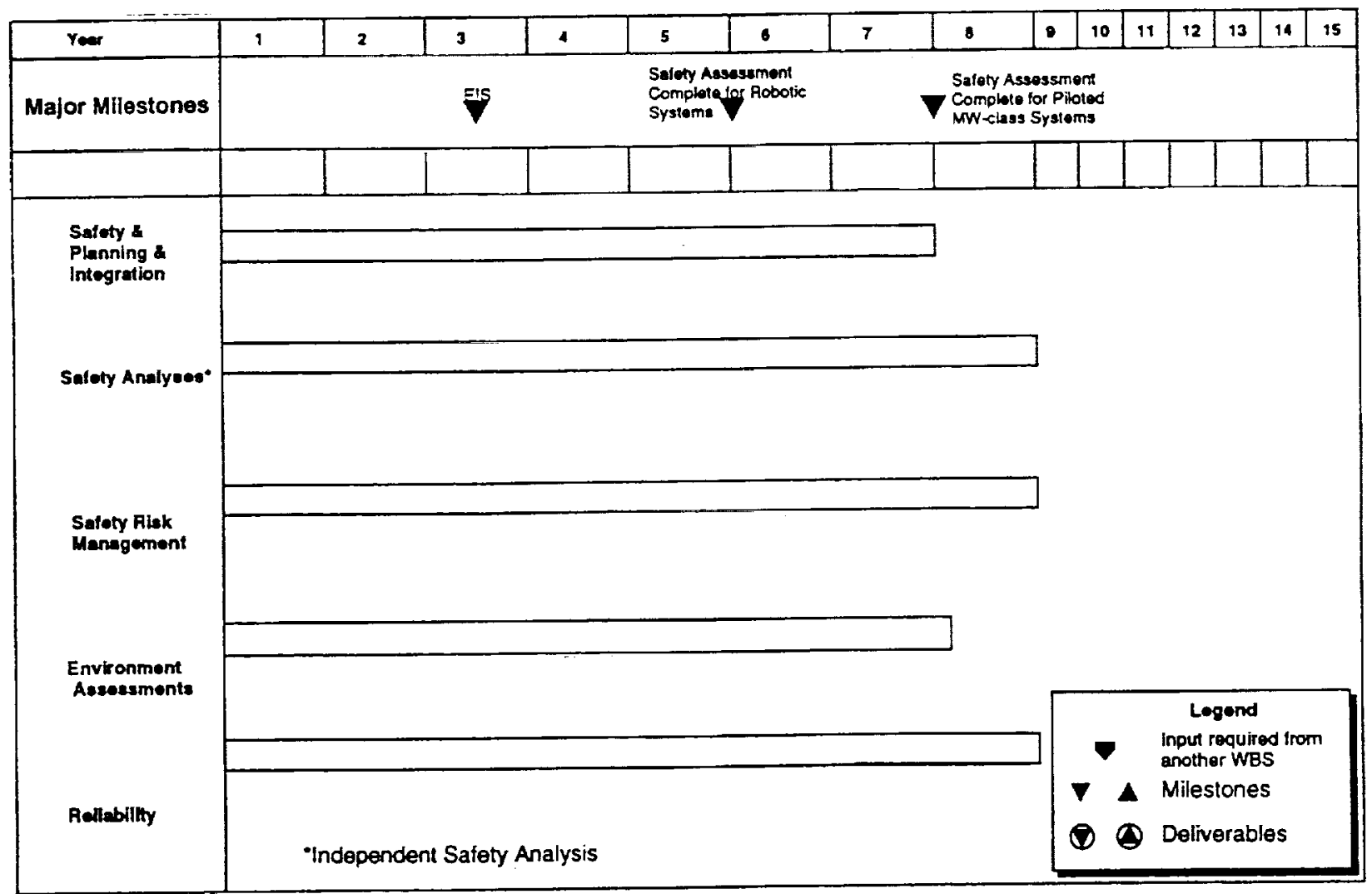

Figure 10. - Safety, Reliability, and Quality Assurance Plan 
6. "Proceedings of the Nuclear Electric Propulsion Workshop, Volume I: Introductory Material and Thruster Concepts, A Joint NASA/DOE/DOD Workshop," Proceedings of Meeting held at Pasadena Convention Center, sponsored by the Jet Propulsion Laboratory, Document JPL D-9512, Vol. I, May 1992.

7. "Proceedings of the Nuclear Electric Propulsion Workshop, Volume II: Power Concepts and Special Presentations, A Joint NASA/DOE/DOD Workshop," Proceedings of Meeting held at Pasadena Convention Center, sponsored by the Jet Propulsion Laboratory, Document JPL D-9512, Vol. II, May 1992.

8. Stone, J.R., Peecook, K.M., and Sovey, J.S., "NASA's Nuclear Propulsion

Technology Project," 10th Symposium on Space Nuclear Power and Propulsion, Albuquerque, NM, Jan. 1993, AIP Conference Proceedings 271, Part 1,pp. 185-197.

9. Stone, J.R. and Sovey, J.S., "NASA's Nuclear Electric Propulsion Technology Project," AIAA Paper 9235705, 28th AIAA/SAE/ASME/ASEE Joint Propulsion Conference, Nashville, TN, July 1992.

10. Friedlander, A., "Conceptual Design of a 50-100 kWe NEP System for Planetary Science Missions," Final Report Presentation, Task Order No. 23, Contract NAS3-25809, Science Applications International, Schaumberg, IL, presented at NASA Lewis Research Center, February 18, 1993.

11. "Space Nuclear Power and Propulsion Final Report," (J.H. Greene, NASA CoChairman and A.R. Newhouse, DOE CoChairman) Sept. 15, 1992.

12. Yen, C.-W., H. Harris, J.H. Gilland, and S. Johnson, Presentation to NASA
Headquarters Solar Exploration Division, Jet Propulsion Laboratory, Pasadena, CA, February 23, 1993.

13. Josloff, A.T., D.N. Matteo, and H.S. Bailey, "SP-100 Space Reactor Power System Readiness and Mission Flexibility," 10th Symposium on Space Nuclear Power and Propulsion, Albuquerque, NM, Jan. 1993, AIP Conference Proceedings 271, Part 1,pp. 229-236.

14. Doherty, M.P. and R.S. Holcomb, "Summary qnd Recommendations on Nuclear Electric Propulsion Technology for the Space Exploration Initiative," NSA TM-105707, April 1993.

15. Doherty, M.P., Summary Letter to Industry and for the Record (includes briefing package: Low Pwer NEP for Early Planetary Science Missions), NASA Lewis ResearchCenter, Cleveland, $\mathrm{OH}$, April 28, 1993

16. Gilland, J.H., Personal Communication, Sverdrup Technology, Cleveland, OH, February 1993.

17. Rawlin, V.K. (1992), "Characterization of Ion Accelerating System on NASA's Ion Thrusters," AIAA Paper 92-3827, 28th AIAA/SAE/ ASME/ASEE Join Propulsion Conference, Nashville, TN, July 1992.

18. Garner, C.E., and J.R. Brophy (1992), "Fabrication and Testing of Carbon/Carbon Grids for Ion Engines," AIAA Paper 92-3149,AIAA/ ASME/SAE/ASEE 28th Joint Propulsion Conference, Nashville, TN, 6-8 July 1992.

19. Divan, D.J. and M.H. Kheraluwala (1991), "High Power Density DC-DC Converters for Aerospace Applications," NAG3-804 Final Report, University of Wisconsin, Madison, WI, 1991. 
Public reporting burden for this collection of information is estimated to average 1 hour per response, inclucing the time for reviewing instructions, searching existing data sources, gathering and maintaining the data needed, and completing and reviewing the collection of information. Send comments regarding this burden estimate or any other aspect of this collection of information, including suggestions for reducing this burden, to Washington Headquarters Services, Directorate for Information Operations and Reports, 1215 Jefter
Davis Highway, Sulte 1204, Arlington, VA 22202-4302, and to the Otfice of Management and Budget. Paperwork Reduction Project (0704-0188). Washington, DC 20503.

\begin{tabular}{|l|c|c|}
\hline 1. AGENCY USE ONLY (Leave blank) & $\begin{array}{c}\text { 2. REPORT DATE } \\
\text { June } 1993\end{array}$ & $\begin{array}{c}\text { 3. REPORT TYPE AND DATES COVERED } \\
\text { Technical Memorandum }\end{array}$
\end{tabular}

4. TITLE AND SUBTITLE

5. FUNDING NUMBERS

NASA's Progress in Nuclear Electric Propulsion Technology

6. AUTHOR(S)

WU-584-04-21

James R. Stone, Michael P. Doherty and Keith M. Peecook

7. PERFORMING ORGANRATION NAME(S) AND ADDRESS(ES)

8. PERFORMING ORGANIZATION REPORT NUMBER

National Aeronautics and Space Administration

Lewis Research Center

$E-8000$

Cleveland, Ohio 44135-3191

9. SPONSORING/MONITORING AGENCY NAME(S) AND ADDRESS(ES)

10. SPONSORING/MONTORING AGENCY REPORT NUMBER

National Aeronautics and Space Administration

Washington, D.C. 20546-0001

NASA TM-106272

AIAA-93-1936

\section{SUPPLEMENTARY NOTES}

Prepared for the AIAA 29th Joint Propulsion Conference and Exhibit, cosponsored by the AIAA, SAE, ASME, and ASEE, Monterey, California, June 28-30, 1993. Responsible person, James R. Stone, (216) 891-2172.

12a. DISTRIBUTION/AVAILABILTYY STATEMENT

12b. DISTRIBUTION CODE

Unclassified - Unlimited

Subject Category 20

13. ABSTRACT (Maximum 200 words)

The National Aeronautics and Space Administration (NASA) has established a requirement for Nuclear Electric Propulsion (NEP) technology for robotic planetary science mission applications with potential future evolution to systems for piloted Mars vehicles. To advance the readiness of NEP for these challenging missions, a near-term flight demonstration on a meaningful robotic science mission is very desirable. This paper briefly reviews the requirements for both near-term and outer planet science missions and describes the near-term baseline system established under a recent study jointly conducted by the Lewis Research Center (LeRC) and the Jet Propulsion Laboratory (JPL). Technology issues are identified where work is needed to establish the technology for the baseline system, and technology opportunities which could provide improvement beyond baseline capabilities are discussed. Finally, the plan to develop this promising technology is presented and discussed.

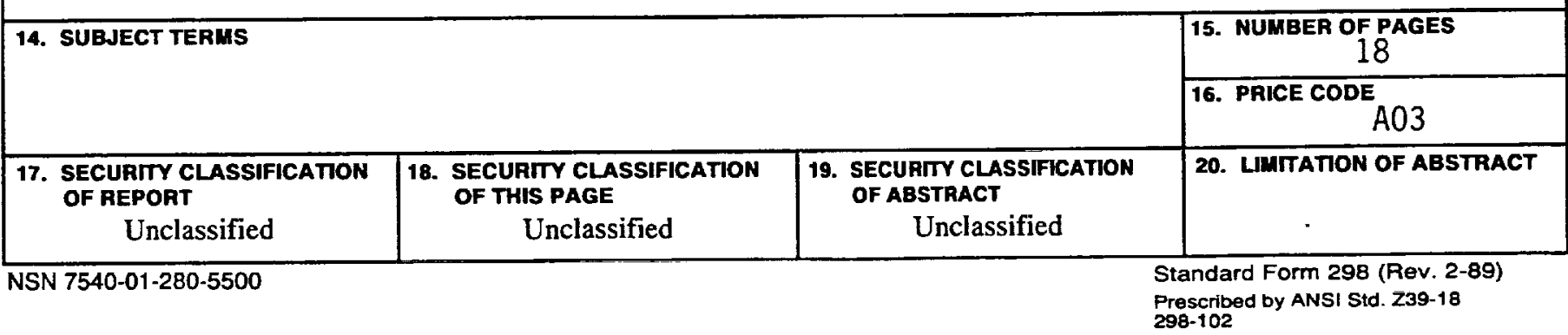


